\title{
Evaluation of Universities' Distance Education by Students and Academicians in the COVID-19 (Coronavirus) Period: A Qualitative Research
}

\author{
Samet Zengin (Corresponding author) \\ Faculty of Sport Sciences, Trabzon University, Trabzon, Turkey \\ E-mail: sametzengin@trabzon.edu.tr
}

Fatih Kirkbir

Physical Education Department, Karadeniz Technical University, Trabzon, Turkey

E-mail: fatihkirkbir@gmail.com

Received: November 5, 2021 Accepted: December 3, 2021

Published: December 31, 2021

doi:10.5296/jei.v7i3.19154 URL: https://doi.org/10.5296/jei.v7i3.19154

\begin{abstract}
The aim of the study is to evaluate the perspectives of students and academicians about distance education implemented by universities in the epidemic period and to determine the advantages and disadvantages of distance education to get an overall perspective. In the study, the data were obtained as a result of in-depth interviews with 12 students and 13 academicians. MAXQDA analysis program was used to analyze the data. The coded data were themed and analyzed. As a result of the analysis, concept maps were created and the analysis process was completed with interpretation. Conclusion of this study, the advantages and disadvantages of distance education applied by universities during the coronavirus period were evaluated. Recording the classes within the scope of distance education has given students the opportunity to review the classes. In this process, it is seen that education/training activities continue without any limitations on time and place. With distance education, it became possible to teach more than one class simultaneously. In this way, it became possible to reach more students in a shorter time. However, it has been found that the level of interaction between the academician and the student decreases in the distance education classes. As such, a decrease in motivation has been detected. Due to the COVID-19 pandemic, a rapid transition to distance education was made, and this rapid transition caused
\end{abstract}


infrastructure and system problems. On the other hand, it is understood that a sound measurement and evaluation cannot be made in the exams applied in the distance education process.

Keywords: University, Academician, Student, COVID-19, Qualitative research

\section{Introduction}

The World Health Organization (WHO) declared the COVID-19 outbreak as a public health and emergency of concern in January 2020. All over the world, efforts are being made to find solutions for prevention and treatment of this epidemic. It is known by everyone that COVID-19 also disrupted the social and economic order of the world (Bobdey \& Ray, 2020). Epidemic diseases cause negative consequences such as sudden deaths, population losses, cessation of production activities, and serious damage to economies (Gülçiçek, 2019). In addition, epidemic diseases negatively affect the educational activities of societies. Educational activities are interrupted in societies due to the epidemic, and distance education is implemented instead of formal education.

Distance education refers to the form of education that takes place when students and teachers are physically located in separate environments. The history of distance education goes back to the 1800s (Akdemir, 2011). Distance education started to emerge all over the world in the 1980s due to the developments in television broadcasting and gained momentum with the development of internet networks towards the end of the 1990s (McIsaac, 2002). The main reason for the implementation of distance education on the internet is the phenomenon of interaction. The fact that the source is the receiver and the receiver is the source constitutes the essence of the concept of interaction. Conducting classes mutually has brought along interactive teaching technologies. As such, the internet-based distance education model has become an important service that is widely used today (Rovai \& Barnum, 2003).

Development of distance education in Turkey have continued to develop, though not at the same speed, in the framework of similar applications to those of other countries. In this context, applications that started with Anadolu University's open education programs for the first time in 1982 increased with the widespread use of computer networks in the 1990s (Kırık, 2014). Education is a set of activities carried out regularly in order to support the process of personal development (Çetin et al., 2004). Distance education is the form in which the interaction between students and teachers takes place in printed or electronic media (Aydın, 2005). Distance education is important in terms of continuing education/training activities in situations where distance may be an obstacle to receiving education (Newby et al., 2006).

As the number of online classes increases in educational institutions and universities, the interest in distance education programs increases as well. Knowledge level and ability to use internet technologies of students affect their attitudes towards distance education and their academic performance in distance education classes (Foshay \& Bergeron, 2000). The technology that is rapidly developing and the ease of accessing the global information pool in a very short time have made the internet a popular tool as an education/training channel. 
Distance education, which is carried out over the internet within the scope of e-learning, online learning, distance-learning, and web-based learning is rapidly spreading in higher education. Many universities have started to give importance to internet-supported distance education in order to meet the changing student needs today (Ally, 2011).

In societies where epidemic diseases occur, negative reflections are seen in economic, social and educational activities. In Turkey, distance education started from the moment the effects of coronavirus (COVID-19) were started to be seen. With the rapid transition to distance education, some problems have occurred in the education system. The fact that the infrastructure of the universities is not sufficient and the academicians and students are not ready for distance education show that the efficiency of education decreases. The fact that both students and academicians are unfamiliar with the distance education model negatively affected this process. It has been observed that taking courses and exams through distance education due to the COVID-19 epidemic has dragged both students and academicians into a psychological chaos. The issues this rapid transition to distance education model brought about started to be seen in one of the universities in Turkey. With the present study, the advantages and disadvantages of the distance education model are attempted to be uncovered.

\section{Method}

\subsection{Objective of the Research}

The current study deals with the distance education system implemented in universities during the coronavirus (COVID-19) period from the perspective of academicians and students. The purpose of the study is to evaluate the perspectives of students and academicians about on education implemented by universities in the time of epidemic and to determine the advantages and disadvantages of distance education to get an overall perspective. With the results to be obtained, it will be determined how the epidemic affects education/training activities and solutions for distance education will be offered within this context.

\subsection{Method and Design of the Research}

Qualitative research method was used in order to evaluate the distance education implemented in universities in the COVID-19 period from the perspective of academicians and students.

Qualitative data analysis is a process where the researcher organizes the data, divides it into analysis units, synthesizes, reveals patters, discovers important variables, and decides what information to present on the report (Bogdan \& Biklen, 1992). The current study is conducted using the phenomenological analysis design, the most commonly used design in qualitative data analysis. Phenomenological analysis is an approach that develops predominantly within existential psychology, and is a type of analysis that is used to understand how people evaluate the events happening in their environment (Wade \& Tavris, 1990). In the phenomenological interview, the researcher attempts to understand how people attribute meaning to external reality (Greasley \& Ashworth, 2007). On the other hand, descriptive analysis technique was also used. In descriptive analysis (Y1ldırım \& Şimşek, 2016), "Direct quotations are frequently used in order to reflect the views of the interviewees or observed individuals in a striking way. 
The aim is to present the findings to the reader in an edited and interpreted manner." In the present study, the views of the participants are often given with direct quotations.

\subsection{Participants of the Research}

In order to obtain qualified and different information, the criterion sampling method, which is a type of purposeful sampling method, was used in the present study. In addition to this method, the snowball technique was also used. According to Creswell and Clark (2018), purposeful sample in qualitative research consists of people who have experience about the basic phenomenon or key concept that researchers examine in their studies and these people are deliberately chosen. One of the common strategies of purposeful sampling is sampling with maximum diversity, which consists of different individuals selected among persons with different perspectives on the central phenomenon. In the present study, a diverse sample has been attempted to be provided. According to Patton, the snowball sampling technique is used when it is difficult to access the units that make up the population or when information about the population is lacking (Patton, 2005). Table 1 shows the interview information of 25 participants, who were reached through criteria and snowball sampling methods used in the study, which are among the purposeful sampling methods.

Table 1. Interview information of the participants (of the participant)

\begin{tabular}{|l|l|l|l|l|l|l|l|l|l|}
\hline Status & Participant name & Gender & Age & $\begin{array}{l}\text { Call time } \\
\text { (Minute) }\end{array}$ & Status & Participant name & Gender & Age & $\begin{array}{l}\text { Call time } \\
\text { (Minute) }\end{array}$ \\
\hline A1 & Mr. Salih & Male & 30 & $24: 05$ & S1 & Mr. Deniz & Male & 21 & $15: 20$ \\
\hline A2 & Mr. Ahmet & Male & 34 & $25: 08$ & S2 & Ms. Aslı & Female & 22 & $14: 45$ \\
\hline A3 & Mr. Ömer & Male & 29 & $18: 22$ & S3 & Ms. Gaye & Female & 23 & $25: 03$ \\
\hline A4 & Mr. Serhat & Male & 28 & $25: 45$ & S4 & Mr. Yasin & Male & 26 & $21: 54$ \\
\hline A5 & Mr. Samet & Male & 32 & $25: 10$ & S5 & Mr. Çağr1 & Male & 28 & $12: 48$ \\
\hline A6 & Mr. Serhat & Male & 32 & $35: 15$ & S6 & Ms. Esin & Female & 22 & $19: 25$ \\
\hline A7 & Ms. Esra & Female & 44 & $15: 32$ & S7 & Ms. Havva & Female & 20 & $18: 36$ \\
\hline A8 & Ms. Şükran & Female & 51 & $10: 18$ & S8 & Ms. Şeyma & Female & 20 & $13: 19$ \\
\hline A9 & Ms. Melisa & Female & 46 & $11: 12$ & S9 & Mr. Koray & Male & 20 & $23: 55$ \\
\hline A10 & Mr. Ferhat & Male & 34 & $20: 05$ & S10 & Ms. Duygu & Female & 20 & $16: 05$ \\
\hline A11 & Mr. Levent & Male & 40 & $07: 45$ & S11 & Mr. Süleyman & Male & 30 & $20: 16$ \\
\hline A12 & Ms. Dilşat & Female & 33 & $11: 28$ & S12 & Mr. Ünsal & Male & 29 & $06: 45$ \\
\hline A13 & Mr. İsmail & Male & 35 & $20: 25$ & & & & & 2 \\
\hline
\end{tabular}

Note. $\mathrm{A}=$ Academician; $\mathrm{S}=$ Student. 


\section{Macrothink}

In the research, a total of 25 interviews were conducted with 13 academicians and 12 students. 4 of the participants were female and 9 were male academicians; 6 were male and 6 were female students. The longest interview took 35 minutes and 15 seconds, and the shortest took 6 minutes and 45 seconds. Some of the participants were interviewed face-to-face, some by phone. In this process, the statements of the participants were recorded in full. Some parts of the notes have been repeated and reinforced. It was decided that interviewing 25 people was sufficient when the data started to be repeated and became saturated.

\subsection{Data Collection Method and Process of the Research}

In-depth interview technique was used using the semi-structured interview form created by the researchers. Interview data were recorded with a tape recorder or by taking notes, depending on the participant's approval. The interviews were completed within a 3-month period in April-May-June 2020. During this time, academicians and students from different universities located in Turkey were contacted and interviews were conducted.

\subsection{Analysis of Research Data}

In the present study, interpretive phenomenological analysis was used. In addition, descriptive analysis technique was used as well. The analysis process in qualitative research includes pre-reading the data, coding and organizing the data into common themes, and finally interpreting the data by presenting them with figures or tables (Creswell, 2018). During the analysis process of the study, all the data obtained with a tape recorder was listened to and converted into text on Microsoft Office Word program. It was carefully and meticulously written in order to avoid data loss in the transcription of the recordings. After this stage, it was reviewed again for control purposes. In this way, data loss was prevented and corrections were made in overlooked points. Finally, all the transcriptions were combined and the coding process was started. The coding was meticulously carried out by the researcher. After the coding of the documents was completed, the codes were organized by themes. The codes were organized by themes with the participation of the researchers. Thus, code validity was also ensured. The codes and themes obtained after this stage were analyzed using the MAXQDA 20 Pro Analytics Program, one of the qualitative analysis programs. With the MAXQDA program, the whole analysis process was systematized and carried out as a whole. Concept maps were created as a result of the analysis. The analysis process was completed by interpreting the findings using these concept maps. The following order was observed in the analysis of the data. 


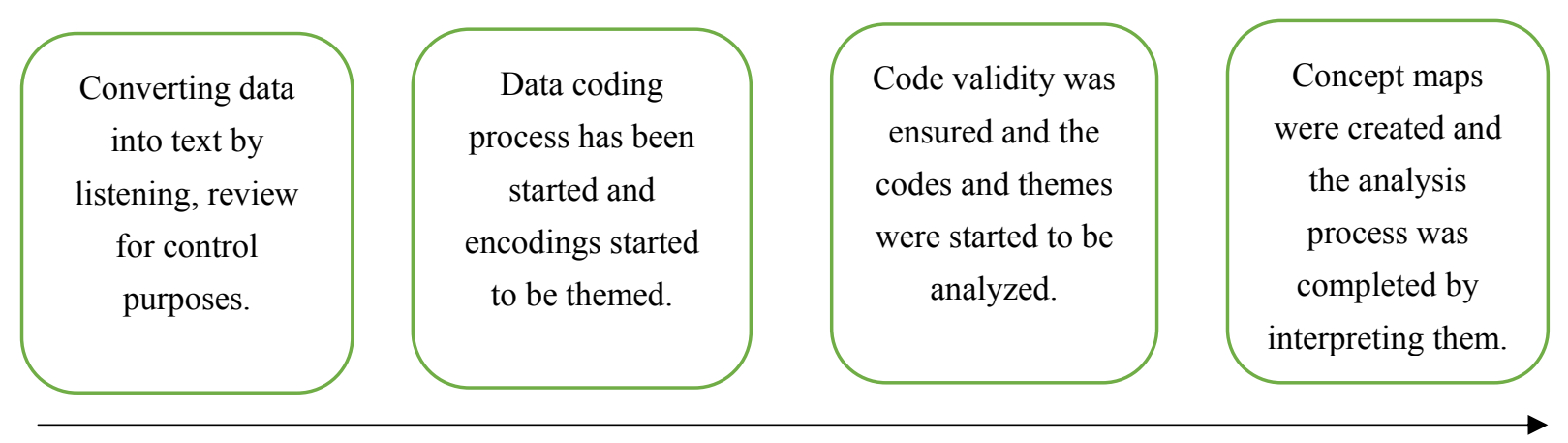

Figure 1. The order observed in the analysis of the data

\subsection{Ethical Procedures}

In the research, the principle of voluntary participation was taken into consideration and the identities of the participants were kept confidential. All participants were informed about the right to leave the research at any time.

\section{Findings}

In this part of the research, findings and comments of the data obtained from the views of academicians and students on "distance education" are included. The data obtained within the framework of four basic questions were coded and subjected to in-depth analysis. The coded data were categorized and collected under certain themes using induction. The codes A1, $\mathrm{A} 2, \ldots \mathrm{A} 13$ for were used the academicians and S1, S2, .. S12 for the students in order to distinguish whom the views belong.

\subsection{Findings Regarding the Evaluation of Distance Education from the Academicians'} Perspective

In this part of the research, the evaluations of academicians about distance education are given. In this part, 4 questions were directed to the participants; themes and codes were created. 


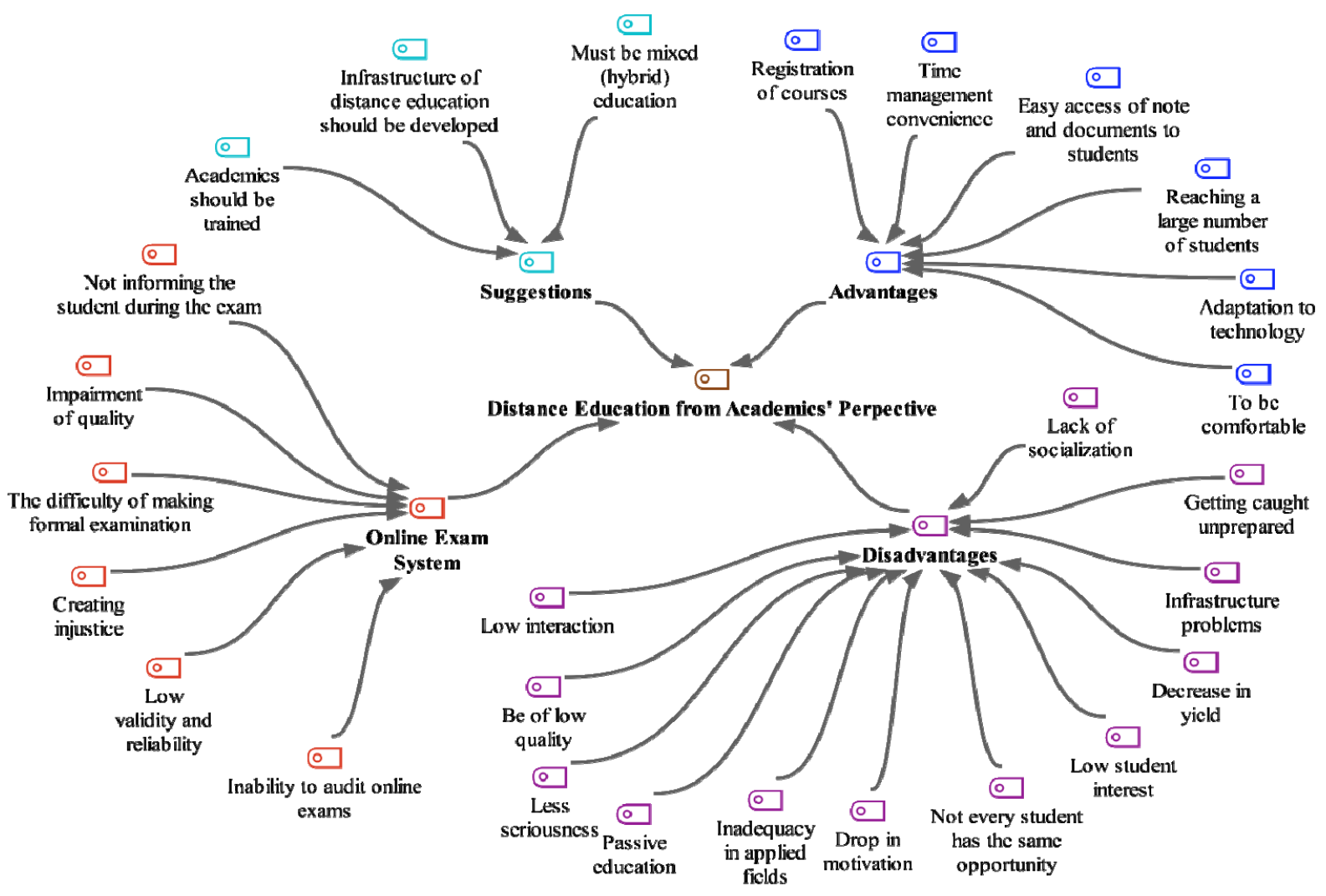

Figure 2. Concept map for the evaluation of distance education from the perspective of academicians

In Figure 2, the conceptual framework of the advantages and disadvantages of distance education from the academicians' perspective, the online examination system and suggestions can be seen in an outline. Academicians' views and evaluations about distance education are discussed in 4 themes. In short, academicians shared their experiences by comparing distance education with formal education.

3.1.1 Findings Regarding the Advantages of Distance Education from the Academicians' Perspective

"Advantages theme" was created in line with the answers given by the participants to the question, "What can you express when you consider distance education in terms of advantages?" and with their coding. Academicians views regarding the advantages of distance education were coded as: "recording courses in distance education," "providing convenience and saving in time management," "being comfortable in distance education," "reaching a large number of students simultaneously," and "adaptation to technology."

Recording the classes taught in distance education and providing the opportunity to watch them again to the students was emphasized as an important advantage. Regarding this, the participants said, "If the student did not attend the class in formal education, it is very difficult to make up for the missed lecture. The student can repeatedly watch and work on the recorded 
lecture in distance education. Distance education offers the opportunity to make up for a missed lecture at any time" (A12, A10, A13).

The online nature of distance education saves academics time. The following statements about this have come to the fore: "I can spare more time for myself in the distance education process. Courses are taught online in distance education. For this reason, factors such as getting up early to go to the campus, getting ready, spending time on the road are out of question. The time we used to spent on these remains to us now" (A2). "Distance education provides comfort and advantage in terms of time. We teach the course within the scope of the curriculum, but we have the opportunity to do the lectures on any day and time we wish" (A3) and (A9). "First of all, I can say that it provides convenience in time management. I can project as many different sources as I want on the screen during the lecture. The saved time allows me to devote more time to my academic studies" (A4).

Academicians talk about the convenience of distance education. They stated that they can teach at home without going to campus. In addition, they stated that they could easily teach classes wherever internet connection is available. In this context, (A1) stated, "One of the advantages of distance education is that lecturing is less tiring for me. During distance education, I do not lecture in a loud voice like in the classroom. I make less effort in lecturing and I am less tired. Since I am at home during distance education, I can spend more time with my family. When lecturing from home, I can put on a comfortable outfit and teach a class." (A2), on the other hand, states that "Because we teach the classes in a home environment, if I need water, tea, coffee, etc. during the lesson, I can easily access them and give the lecture more comfortably."

Finally, in the context of advantages, academicians stated that distance education provides the opportunity to reach a large number of students and that documents can be easily delivered to students. The statements of the two participants on this subject are as follows: "While a certain number of students can be reached in the classroom in formal education, a larger number of students can be reached simultaneously in distance education" (A12) and "Compared to formal education, distance education provides the opportunity to teach more students at the same time" (A13). The statement of an academician who said that the lecture notes in distance education are transferred to the students easily is as follows "Distance education has its advantages. For example, I can easily transfer some documents in distance education that I could not transfer to students during the lecture in formal education" (A1). Finally, about adaptation to technology (A5) made the statement, "We know we are in the digital age. It made me see that theoretical lessons can be taught through distance education."

3.1.2 Findings Regarding the Disadvantages of Distance Education from the Academicians' Perspective

In this section, findings regarding the academicians' views on the disadvantages of distance education are given. Participants were asked the question "What are your thoughts when you consider distance education in terms of its disadvantages?" According to the answers from the participants, the disadvantages theme and the codes for this theme were created. Within the scope of the disadvantages theme, the codes "low interaction," "inadequacy in applied areas," "passive education," "low motivation," "decrease in seriousness," "decrease 
in quality," "decrease in efficiency," "failure of socialization," "low interest of students for the classes," "infrastructure problems," "not every student has the same opportunity," and "caught off guard" came to the fore. When we consider the disadvantages theme within the scope of these codes, the following statements stand out:

Academicians emphasize low quality and class efficiency in distance education with the following statements: One participant (A5), states "I think there are various deficiencies in terms of quality in the classes taught in the distance education process" claiming low quality in lectures. Regarding the decrease in class efficiency, (A1) states "Instead of actively teaching in the classroom, giving internet-based lectures reduces the efficiency of the lecture. In formal education, I see students live and I can understand whether students are listening to the lecture or not. However, in distance education, the student only logs into the system and we cannot follow whether they listen to the lecture or not." Another participant (A3) states, "Lecturing within the scope of distance education becomes weak. We cannot teach the classes face-to-face as in formal education, so we cannot convey detailed information on the material to the student." Thus, it can be stated that distance education raises question regarding quality and efficiency.

The low interest of students in distance education to lectures causes low motivation in academicians as well. Regarding the interest of the students to the lectures, the academicians stated the following; "Students appear to be attending the lecture in the system, but many of them do not participate actively in the class. The students are not interested in the lesson. I ask questions in distance education and questions are usually answered through the chat section. As such, the lecture does not progress smoothly" (A6). "Very few people answer the question I ask during the lecture in distance education. I see that the number of students attending the lecture during class is very low compared to the class size. In short, the interest shown to the lecture is not enough" (A1). "While it is possible to draw the attention of the most uninterested students in the classroom in formal education, it is not possible in distance education. The replies we get to the questions we ask is inadequate." (A7).

When such situations occur, the motivation of the academicians during the class decreases. Academicians used the following statements; "The number of students attending classes in distance education is insufficient. Since we are not used to the system, the lectures are not as interesting as in formal education. Interest of the students is insufficient, which decreases my motivation to lecture" (A4) and (A12). "The adaptation problem of students to distance education disrupts the course flow. As such, our motivation towards the class decreases. All of these appear as factors that make distance education difficult." (A5). "One of the biggest factors that challenges me in distance education is lecturing without communicating face to face with students. My motivation decreases when I teach in this way" (A1) and (A3). Lastly, (A7) stated that "Giving our lectures in a virtual environment has greatly damaged the enthusiasm of teaching, which every academician should enjoy."

The low academician-student interaction in distance education decreases the seriousness of the lecture. As such, an unilateral education structure emerges. For these reasons, academicians criticize distance education. An academician emphasizes the decrease in the seriousness of the 
class as follows; "In formal education, students and we meet in the classroom to lecture and listen, creating a serious environment to listen to the lecture. In distance education, the student can log into the system during the lesson and do other things in the background. This situation decreases the seriousness and interest in the lesson" (A3). "Formal education keeps the motivation of students and academicians alive. Social and academic interaction established in formal education does not seem possible in distance education" (A9). "While academician-student interaction is higher in formal education, this interaction becomes weaker in distance education" (A10). "Since I cannot see the reactions of the students during the lecture, I always face a deadlock about how much of the subject is understood" (A13). Lastly, (A8), states, "I believe that academicians and students should establish a healthy communication in education. The opportunity to do this becomes limited in the digital environment" arguing that the interaction in distance education is low.

Academicians claim that distance education is academician-centered, one-sided, and passive. Two academicians, (A2) and (A3), state "In distance education, students attend the lecture less than in the classroom environment. Whether the lectures taught in distance education are listened to and understood by the student cannot be understood by the academician. One-sided lecture takes place. While lecturing, I ask questions, but almost no student responds. Even though I ask 'Are there any questions?' But I receive no reactions."

Academicians state that distance education is insufficient in applied fields (medicine, nursing, sports sciences, etc.). It is emphasized that the applied courses are difficult to handle and in some cases cannot be taught at all. Some of the academicians' views on this issue are as follows: "Not being able to teach applied courses is a factor that limits me. Lack of both practice environment and practice-oriented equipment prevents the course from being taught" (A3) and (A2). "Applied courses do not seem possible in the online system. It will be healthy to continue with formal education especially for applied courses" (A6). "In the current system, I can only teach theoretically" (A2).

Factors such as "not every student having the same opportunities," "inadequate distance education infrastructures of universities," and "universities being unprepared for the distance education model that was implemented due to the pandemic," were cited as disadvantages of distance education by academicians. For example, a participant (A1) stated "I think distance education has beneficial aspects. Nonetheless, starting this process without being prepared has put us in a difficult situation. Since we did not have a preliminary preparation, both academicians and students approached distance education with prejudice" and "during the distance education process, we have seen that most universities are not prepared for this system" claiming that there was a rapid transition to distance education model due to the pandemic and that they were caught unprepared.

Some academicians have expressed the infrastructure problems regarding distance education with the following statements: "Since the distance education infrastructure is not strong, the lecture process becomes weak. We do not know how much the student understands and learns what we want to express and convey" (A1). "During this process, I experience problems such as poor sound quality and intermittent disconnection while lecturing. Some students state that 
my voice is low. Also, due to the occasional disconnection, I spend time trying to reconnect, join the class, and continue where we left off. These situations disrupt the integrity of the lecture subject" (A2) and (A9). Finally, not all students having the same opportunities is also stated as a disadvantage in distance education. An academician (A9) stated the following about this: "Not every student has electronic devices such as computers and tablets. Most students do not even have access to internet. As such, it is not a healthy situation for me to lecture." Other academicians, (A13) and (A2), stated "The biggest problem in distance education is that internet, computer or telephone facilities are limited. It can be disadvantageous especially for students in rural areas."

3.1.3 Findings Regarding Online Exams in Distance Education from the Perspective of Academicians

Academicians were asked "What are your thoughts on online exams implemented in the distance education process?" The answers received were analyzed under the theme of "online exam system." Academicians mentioned problems such as "the exams cannot be inspected," "the validity and reliability are low," "low quality," "the difficulty of making classical exams," "the occurrence of injustices and students not being informed during the exam" related to online exams in distance education.

Some academicians offered the following opinions about the inability to inspect online exams: (A6) stated, "It is not possible to check on the students during exams. We ask a certain number of questions through the system and give a certain amount of time. We cannot determine whether the exam is conducted by the student or not. Also, we cannot see if there is any kind of cooperation during the exam" (A11) and (A2), on the other hand, offered their thoughts by stating "there is no control mechanism on the students during the online exam. As such, we do not have any information about how and in what way the questions are answered in the background."

In addition, it is stated by the academicians that the exams in distance education are not appropriate in terms of measurement and evaluation. For example, regarding the exams, an academician's (A5) statement is striking: "I can say that the overall reliability of online exams is low. Unfortunately, in this process, we saw that students got high scores by solving exam questions using communication tools in online exams. I do not think the exams taken during this period are valid and reliable." Other academics (A9) and (A13) stated the low quality in the following statements they made: "I think that the validity of online exams is low. Because it is not possible to control students in exams."

On the other hand, an academician (A6) said about online exams, "I can say that the quality of online exams is low." Another participant stated that they could not ask open-ended questions in online exams with the following sentence: "Multiple choice questions are easily done in online exams, but it is not possible to ask open-ended questions and get answers." An academician (A2) commented as follows to express that they cannot inform students during the online exam: "In formal education, we can give information about the exam beforehand. In fact, if there is a question that the student does not understand during the exam, we can provide an explanation, if only about the question. Nevertheless, we can only provide information about 
the duration of the online exams that we apply in the distance education process." Finally, an academic (A6) who stated that there is a cheating situation during the online exam system, states that this situation creates injustice among students: "As such, we cannot distinguish between students who work and take interest in the classes, and those who do not. During the online exam, the student does not have a chance to ask us questions. As such, it is not possible for us to provide an explanation. In general, the quality of the exams should be discussed."

\subsection{Findings Regarding the Evaluation of Distance Education from the Students' Perspective}

This section contains the findings of students' views on distance education. Students' views on distance education are similar to those of academicians. However, it is worth noting that there are differences in some points.

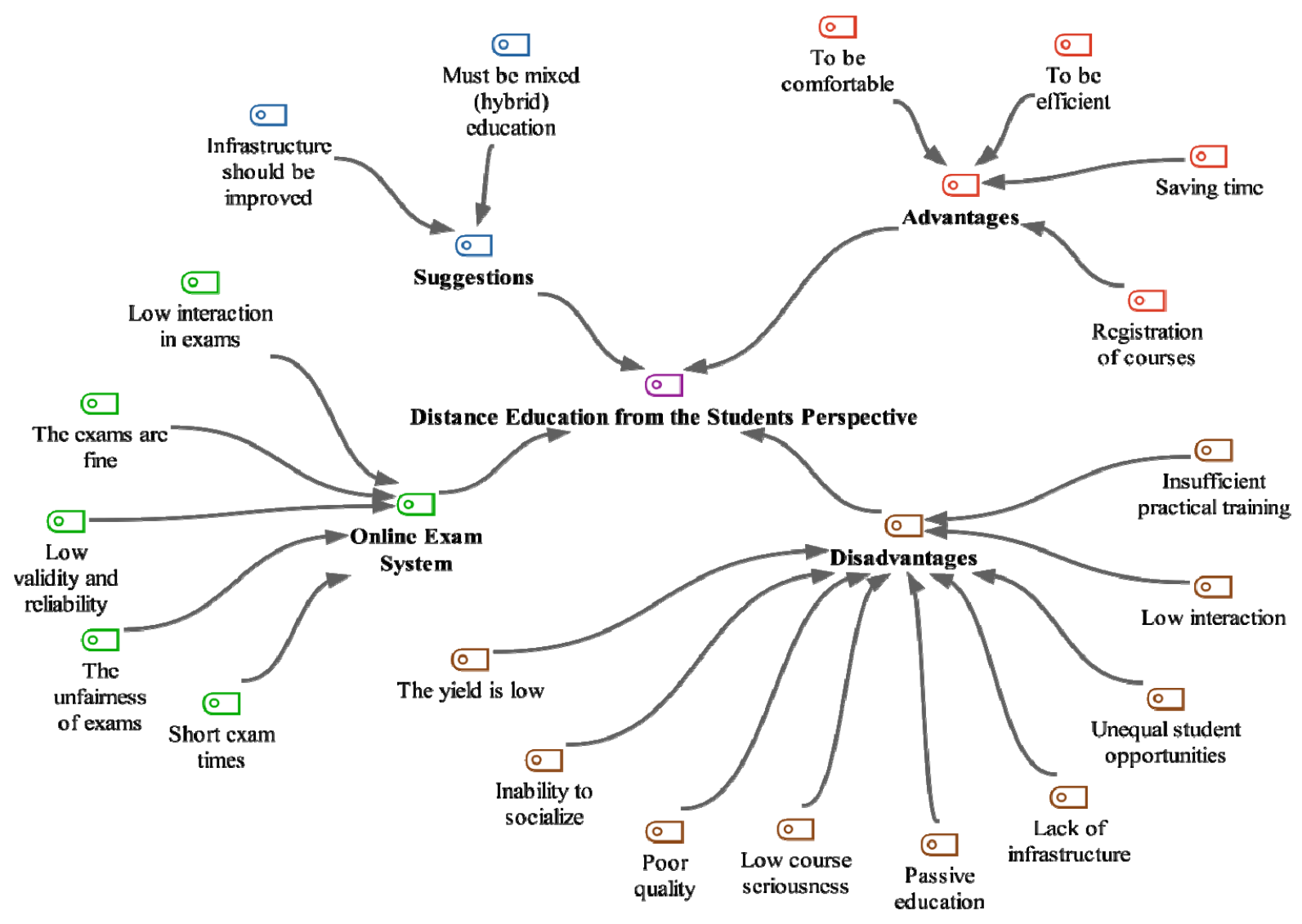

Figure 3. Concept map for the evaluation of distance education from the perspective of students

In Figure 3, the conceptual framework of "advantages," "disadvantages," "online exam system," and "suggestions" of distance education from the students" perspective can be seen in its baselines. Students' views and evaluations of distance education are discussed within these 4 themes. 
3.2.1 Findings Regarding the Advantages of Distance Education from Students' Perspective

"Advantages theme" was created in line with the answers given by the students to the question, "What can you express when you consider distance education in terms of its advantages?" and with their coding. The statements made by the students in the context of advantages of distance education are similar to those of academicians. The answers received from the students were coded as "recording distance education lectures," "providing convenience and saving in time management," "being comfortable in distance education," and "being efficient."

The students state that distance education provides great convenience in terms of time with the following statements: "I can say that distance education saves time. We can attend the lectures from home. Thus, we can spare time for our other activities" (S3). "We have saved time in distance education. I can wake up shortly before the class starts and attend the class. We have the chance to turn the crisis into an opportunity in terms of time" (S2) and (S5). "Distance education offers us the opportunity to learn without time and place limitations" (S6).

The students stated that distance education is both comfortable and they are satisfied with the lecture recordings. Regarding the convenience of distance education, students (S10) and (S9) commented: "first of all, distance education offers economical convenience. It is possible to reach a large number of people with distance education. Students who cannot attend school due to some reasons can log in to the system and listen to the lectures from wherever they want." Students (S1) and (S10) regarding the registration of courses, commented "By having the lectures recorded in the system, students can log in to the system and watch the lectures whenever they want. This is a good opportunity for us. I can say that distance education is beneficial in this aspect." On the other hand, a student (S12) stated the following about the efficiency of distance education: "If I consider the distance education system within the scope of my university, I can say that it is very efficient. In fact, it would not be wrong to say that it is applied in many subjects without any difference from face-to-face education. I can express that I learned more in detail by doing research on many subjects in the distance education process."

\subsubsection{Findings Regarding the Disadvantages of Distance Education from the Students'} Perspective

Under the disadvantages theme, created within the scope of distance education, the following codes came to the fore: "Lack of efficiency," "failure to socialize," "low interaction and quality," "passive education," "decreased seriousness of the lesson," "lack of infrastructure," "unequal opportunities of the students," and "inadequacy in applied classes." Students discussed the disadvantages of distance education within the framework of these concepts.

The students expressed the low efficiency and quality in the distance education process by comparing it with formal education as follows: "formal education was carried out in the classroom environment. At that time, we could ask what we wondered about the lecture there and then, and get an answer. Albeit, when we ask a question about something in distance education, some time passes until we get an answer. As such, the lecture flow gets interrupted. 
In formal education, having face-to-face lectures and creating a discussion environment related to the lecture increased our chances of learning the subject permanently. However, in distance education, lectures are taught in a one-sided manner over the lecture material the academician displays on the screen" (S7). "I think this process negatively affected me. Academicians lecture over the presentation. Except for the slides prepared about the lecture, nothing is explained. This system reduces the student's motivation to study. There is no synergistic environment during the lecture" (S6). On the other hand, a student (S6) commented about the low quality of distance education, "I think that formal education is more beneficial as I am a student interested in the lecture. In formal education, academicians may ask questions during lectures. Similarly, we can ask questions about the lecture to our teachers. Therefore, I can say that formal education has many benefits in terms of teaching and learning. Learning the material in formal education permanently is extremely effective."

Students express the decreased seriousness in distance education as follows: "There is no seriousness as there was in the classroom. Academicians only lecture and we listen quietly in front of the screen. As such, our interest in the lecture decreases. The system is open during the lecture, but we have the opportunity to do other things. In formal education, we were in a classroom environment. This increased my interest and seriousness during the lecture. We could ask questions to the academician face to face. This situation was keeping my interest in the lecture active. Our questions about the things we were curious about were answered in the heat of the moment" (S8). "Formal education is much more helpful in communication and understanding the lecture. In formal education, we saw the academician and listened to the lecture face to face. We could ask questions whenever we wanted. These things are not possible in distance education" (S2). (S6) and (S7) explained that the lectures are carried out in a non-interactive manner with these words: "the academician conveys the information on the slide to us through the system. As such, we have been deprived of an active lecture process."

Students emphasized low interaction in distance education lectures with the following statements: "During online classes, we do not have the opportunity to ask questions like we had in the classroom. This situation decreases our interest in the lecture. In formal education, we could get answers to questions about the things we were curious in the classroom. After the lecture, we could go to the academician's office and ask what we wanted to ask. These things are not possible in distance education. I would like to state that we generally have problems in communicating" (S9). "It is an undeniable fact that there is no substitute for face-to-face education. While sometimes a glance or a mimic was enough to provide communication and affect the students in education, we are deprived of this in distance education" (S11) and (S5). The students stated enough interaction and communication could not be provided in distance education.

Students seriously emphasize that distance education is insufficient in applied courses. About this, a student (S11) commented, "It is a fact that we feel the lack of applied classes. Learning by practicing-experiencing is the most effective method in education. Though, teaching the courses online prevented this. All courses create a lack on peer learning. The students can easily learn any subject that they could not learn through their friends in formal education. 
However, all these are lacking in distance education." Here, it is useful to underline that applied courses in distance education cannot be carried out.

Students reported that there were problems arising from the systems used by universities in the distance education process. It has been stated that there are problems in both lectures and exams. At the same time, they stated that they experienced serious problems due to poor infrastructure for distance education. About this, (S1) stated, "Due to low internet speed during distance education, live lectures freeze and sometimes the connection is lost. When shooting lecture videos, the sound quality of the videos is quite poor. The noise from the microphone used reduces the quality of the videos. During the lecture, some academicians' eating and drinking can also distract us. I would like to say that the distance education infrastructure is insufficient and we are not used to distance education." Another student (S7) said, "Sometimes problems occur such as slow loading of the relevant pages during exams and errors when opening the page. Some academicians attribute systemic problems to students. In some exams, we see that the exam time is insufficient. In addition, problems arising from the internet affect our exams negatively."

On the other hand, students state that distance education prevents socialization. They stated that social relations between academicians and students do not develop in distance education. It has been stated that formal education is better in this regard. The following statements were made by the students who evaluated the formal and distance education comparatively: "In formal education, students' socialization, self-confidence, participation in the lecture, and success in learning are quite high" (S1). "Formal education is a system that is fundamental in preparing students for professional life. Formal education provides equality of opportunity among students. Formal education has shown that exams are objective and more valid than distance education. Regardless of the conditions, I prefer formal education to distance education" (S9). "In the formal education process, learning is more active and permanent. In addition, we gain different habits in a different city during the formal education process. Making friends has many benefits in terms of sustaining our lives both materially and morally." "Distance education prevents students from socializing" (S10).

3.2.3 Findings Regarding Online Exams in Distance Education from the Perspective of Students

In this section, findings on students' views about online exams within the scope of distance education are given. According to the answers received from the participants, the disadvantages theme and the codes for this theme were created. Within the scope of this theme, codes such as "short exam times," "unfair examinations," "validity and reliability problems of exams," "low academic and student interaction in exams," and "exams being good" came to the fore.

Students criticize many issues within the scope of this theme. The first of these criticisms is that academicians keep exam times short due to the possibility of students cheating during the exam. A student (S1) made the following statements about this: "The durations of some exams are kept short to avoid cheating. When the duration of the exams are short, and the technical problems are added on top of this, our exams do not go well." Another student (S7) said, 


\section{MInstitute Machink $_{\text {Inthe }}$}

"During the online exam, a certain number of questions and a certain amount of time are given. We do not have the opportunity to ask about the questions we do not understand to the academician. In addition, having a technical problem during the exam disrupts us both psychologically and in terms of time."

The students stated that there are concerns about the validity of online exams in distance education: "I can say that online exams are not reliable. The reason is that there is no mechanism that controls us during online exams, and it is possible to benefit from other sources during the exam. As such, it becomes impossible to distinguish the ones that studied for the exam from the ones that did not" (S7); (S9) and (S6). "I think online exams do not measure the level of knowledge. When the exam is held online, I can say that the validity of the exam is low. Therefore, I do not think highly of the online exams" (S5).

Lastly, it is stated that the interaction in online exams is low. About this, a student (S4) stated, "We do not have the opportunity to ask questions to the academicians during the online exam. Whereas if we had any questions in the classroom environment in formal education, the academician could give information about the question. However, this is not the case during online exams."

\subsection{Suggestions for Distance Education from the Perspective of Academicians and Students}

Finally, the answers we received to the question "What are your suggestions for distance education?" which we asked both academicians and students, were collected under the theme of "suggestions." Regarding this theme, the views that came to the fore are "infrastructure related to the distance education system should be improved" and distance education and formal education should complement each other as a "hybrid" model. It has been deemed appropriate by both academicians and students to conduct some courses through distance education.

The views of both students and academicians regarding the development of distance education infrastructure are as follows: "The distance education infrastructure needs to be further strengthened. A strong distance education system will increase the quality of the lectures taught" (A1). "For distance education, infrastructure of the university must be strong. Students and academicians should be given detailed information and training on distance education" (S1). "The distance education system can be further strengthened. If an environment is created in which students and academicians can see each other with a camera, the atmosphere of being taught face to face may be created as in the classroom environment" (A3). "Distance education infrastructures of universities should be further strengthened" (A4, A11, A13). "Universities should strengthen their infrastructure for distance education before starting education" (S11).

Academicians and students emphasized that the distance education model should be applied together with formal education (mixed) in the following process. Related to this, some academicians (A10, A9, A12, A13) stated, "I think distance education is necessary. Except that, distance education alone is not enough. It will be more beneficial to use it as a support for formal education." Along with these, a student (S10) said, "Distance education should be included in education, albeit partially. It may be possible to teach some courses using the 
distance education system." Another student (S9) said, "Formal education should continue as long as the circumstances allow. It may be possible to teach some classes in distance education. Homework can be given. However, it will not be beneficial for students to carry out education completely in the form of distance education." Finally (S3) commented "distance education should not replace formal education. It can partially take part in education life. Because while it is possible to teach theoretical courses through distance education, it is not possible to teach applied courses and get efficiency through distance education."

\section{Discussion}

In this part of the study, distance education implemented in universities was evaluated by academicians and students, and the results obtained were compared with other studies in the literature.

In the present study, it was stated that distance education has many advantages by both academicians and students. Recorded courses, saving time, and reaching a large number of students simultaneously are important advantages. In addition, it is possible to offer classes in a place independent of campus in distance education.

There are studies on distance education in the literature. Looking at the relevant studies, it is seen that providing courses and documents on the internet in higher education provides economic benefits in terms of time and cost. It also offers academicians the opportunity to teach independently from traditional settings (McBurnie, 2002). In addition, as a result of the opportunities provided by technology, distance education provides people with the opportunity to turn to an area of interest in any period of their lives and to receive education in subjects they are interested in whenever and wherever they want (Oktay, 2001).

In the present study, it was stated by both academicians and students that distance education has many disadvantages. These are disadvantages such as low interaction, decrease in efficiency in lectures, lack of socialization environment, system-related infrastructure problems, and inability to teach applied courses.

There are studies conducted on distance education in the literature. It is seen that students who take part in the distance education system are faced with many problems such as being obliged to continue their education on their own, not being motivated, lack of communication and interaction, etc. (Ekici, 2003). In a study, it is stated that academicians spend more time in the distance education process compared to normal education, so the execution of the process is more laborious and difficult (Karaman, 2007). In a different study, a lack of face-to-face communication was observed in web-based distance education programs. When technology facilities are not used correctly, the expectations of the students are not met and the students leave the system feeling alone (Bilgiç \& Tüzün, 2015). It has been found that $75 \%$ of students studying online in the USA leave the system before completing their education. This shows that distance education brings many problems with it (Karpenko, 2008).

As a result of the present study, suggestions were made by both academicians and students for distance education. Suggestions that were made for distance education are improving the 
infrastructures of universities, adopting the co-education model, and using distance education as a support for formal education.

When the literature is examined, we see that studies have been carried out on the relevant subject. In a study, it is suggested that universities should review their distance education infrastructures and give weight to infrastructure investments that will make the education model a powerful web-based system (Düzakın \& Yalçınkaya, 2008). In some studies, instructors prefer to use distance education together with face-to-face education (Orhan et al., 2004; Seng \& Mohamad, 2002). In addition, it is stated that the web-based distance education system is not seen as a competitor of the traditional formal education system. This system should have a feature that greatly increases the quality of formal education (Düzakın \& Yalçınkaya, 2008).

\section{Conclusion}

In this current section, the advantages and disadvantages of distance education from the perspective of academicians and students, and results of evaluations related to online exams are included. In this context, we can first consider the advantages of distance education from the perspective of academicians. Academicians stated that distance education have advantages such as recording the lectures taught, saving time, and being able to reach many students simultaneously. When we look at the details of the relevant statements, it is advantageous for both academicians and students to record the courses. Students who cannot attend the lecture have the opportunity to $\log$ in to the system and watch the recorded lectures. Due to such an advantage, the missed lectures can be compensated and the continuity of education will be possible. Distance education provides great convenience to academicians in terms of time. The online classes save time for academicians on many things during the day. When all these advantages are evaluated, we can say that distance education supports formal education.

Academicians also emphasize the disadvantages of distance education. Factors such as low interaction during the lecture, not being able to teach applied classes properly, insufficient infrastructure of the universities for distance education, and the decrease of students' interest in the lecture are included within this scope. It was found that students did not show interest in the class because the lectures could not be conducted face to face. In addition, it was observed that the questions asked by the academician during the online lecture were not answered. As such, academicians stated that their motivation decreased. Academicians made comments on the issues such as low validity and reliability for online exams conducted in the distance education process, the difficulty of conducting exams with open-ended questions, and the absence of control mechanism over students during the exam. Online exams are conducted through the online system. The occurrence of technical problems puts students in a difficult situation.

Students stated that distance education has advantages such as recorded lectures, convenience, and saving time. The recorded lectures provide a great advantage for students. It offers the opportunity to watch the lectures over and over again whenever desired. Having such an opportunity enables the students to review the lectures. Students also emphasize the 
disadvantages of the distance education system. It is emphasized that there is no socialization environment in the distance education process, the mutual interaction is low, the distance education infrastructure of the universities is insufficient, and the applied courses cannot be taught. Regarding the online exams that take place in the distance education process, factors such as the short duration of the exams, the hesitation about the validity and reliability of the exams, and the absence of interaction during the exam are expressed. During the exam in formal education, students can ask questions to academicians. However, this is not possible in distance education. The academician directs the exam questions through the system, and the students answer the questions. Unclear questions are not clarified. As a result, both academicians and students expressed positive and negative views on the distance education system. They expressed the advantages and disadvantages of distance education. In the light of all these results, it is understood that distance education is a weaker system than formal education. However, considering its advantages, it is concluded that it would be beneficial to implement distance education as a support for formal education.

\section{References}

Akdemir, O. (2011). Teaching math online: Current practices in Turkey. Journal of Educational, Technology Systems, 39(1), 47-64. https://doi.org/10.2190/ET.39.1.e

Ally, M. (2011). Foundations of Educational Theory for Online Learning. Theory and Practice of Online Learning. Athabasca University.

Aydın, C. H. (2005). Learners' preferences of communication tone used in the print materials for open and distance learning. Anadolu University Journal of Social Sciences, 5(1), 131-147. Retrieved from https://dergipark.org.tr/tr/pub/auad/issue/34059/376970

Bilgiç, H. G., \& Tüzün, H. (2015). Problems encountered in higher education institutions web-based distance education programs. Journal of Open Education Applications and Research, 1(3), 26-50. Retrieved from https://dergipark.org.tr/tr/pub/auad/issue/3028/42071

Bobdey, S., \& Ray, S. (2020). Going viral-COVID-19 impact assessment: A perspective beyond clinical practice. Journal of Marine Medical Society, 22, 9-12. https://doi.org/ 10.4103/jmms.jmms_12_20

Bogdan, R. C., \& Biklen, S. K. (1992). Qualitative Research for Education: Introduction and Methods. Boston: Allyn and Bacon.

Creswell, J. W. (2018). Qualitative Research Methods. Ankara: Political Bookstore.

Creswell, J. W., \& Clark, V. L. P. (2018). Mixed method research: Design and execution. Ankara: Anı Publishing.

Çetin, Ö., Çakıroğlu, M., Bayılmış, C., \& Ekiz, H. (2004). The importance of education for technological development and the place of internet assisted instruction in education. The Turkish Online Journal of Educational Technology, 3(3), 144-147.

Düzakın, E., \& Yalçınkaya, S. (2008). WEB based distance learning system and distance learning familiarities among members of the Çukurova University. Ç.Ü. Journal of the 
Institute of Social Sciences, 17(1), 225-244. Retrieved from https://dergipark.org.tr/tr/pub/ cusosbil/issue/4378/60019

Ekici, G. (2003). The importance of students' learning styles for selecting distance educational mediums. Hacettepe Üniversitesi Eğitim Fakültesi Dergisi, 24, 48-55.

Foshay, R., \& Bergeron, C. (2000). Webbased education: A reality check. TechTrends, 44, 16-19. https://doi.org/10.1007/BF02818231

Greasley, K., \& Ashworth, P. (2007). The phenomenology of "approach to studying": The university student's studies within the lifework. British Educational Research Journal, 32, 819-843. https://doi.org/10.1080/01411920701656977

Gülçiçek, M. (2019). Epidemic Diseases in İzmir Between 1929-1945 and Search for Solutions (Master thesis, Dokuz Eylül University Institute of Social Sciences, Izmir).

Karaman, S. (2007). Course web pages: Features, creation, use and attitudes of lecturers. Inönü University Journal of Education Faculty, 7(13), 47-68.

Karpenko, M. P. (2008). The emergence and development of distance education. Russian Education and Society, 50(3), 45-56. https://doi.org/10.2753/RES1060-9393500304

Kırık, A. M. (2014). Historical development of distance education and the situation in Turkey. Marmara University Journal of Communication, 21, 73-94. https://doi.org/10.17829/midr. 20142110299

McIsaac, M. S. (2002). The internet culture and community building. Advencing online learning in Asia (pp. 16-25). Hong Kong: The Open University of Hong Kong.

McBurnie, G. (2002). Globalization, GATS and transnational education. Educational Sciences in Theory and Practice, 2(1).

Newby, T. J., Stepich, D. A., Lehman, J. D., \& Russell, J. D. (2006). Educational Technology for Teaching and Learning. Upper Saddle River, New Jersey: Pearson Merrill Prentice Hall.

Oktay, A. (2001). New trends and education in the 21st Century. Istanbul: Sedar Education Research Publishing.

Orhan, F., Altun, A. S., \& Kablan, Z. (2004). Based on blended learning method application and student opinions: Yildiz Technical University Example. IV International Educational Technology Conference, 24-26 November 2004, Istanbul, Turkey.

Patton, M. Q. (2005). Qualitative research. New York: John Wiley \& Sons, Ltd.

Rovai, A. P., \& Barnum, K. T. (2003). On-line course effectiveness: An analysis of student interactions and perceptions of learning. Journal of Distance Education, 18(1), 57-73.

Seng, L., \& Mohamad, F. S. (2002). Online learning is it meant for science courses? Internet and Higher Education, 5, 109-118. https://doi.org/10.1016/S1096-7516(02)00087-8 


\section{Macrothink}

Journal of Educational Issues ISSN 2377-2263

2021, Vol. 7, No. 3, Special Issue

Wade, C., \& Tavris, C. (1990). Psychology (2nd ed.). London: Harper and Row Publishing Company.

Yıldırım, A., \& Şimşek, H. (2016). Qualitative research methods in the social sciences. Ankara: Seçkin Publishing.

\section{Copyright Disclaimer}

Copyright for this article is retained by the author(s), with first publication rights granted to the journal.

This is an open-access article distributed under the terms and conditions of the Creative Commons Attribution license (http://creativecommons.org/licenses/by/3.0/). 